\title{
LOS ASENTAMIENTOS CHANKAS: ¿UNA RESPUESTA A LA VIOLENCIA?
}

\author{
Julio ERnesto VALDEZ CÁRdenas \\ UnIVERSIDAD NACIONAL SAN CRISTÓBAL DE HUAMANGA \\ ernestovaldezcardenas@hotmail.com
}

\section{RESUMEN}

En este artículo, después de presentar las características de los sitios arqueológicos llamados Chanka, que corresponden al Periodo Intermedio Tardío, dentro de la llamada Área Histórica Chanka, aquí en los territorios andinos de Huancavelica, Ayacucho y de Andahuaylas, se discute por qué motivos, después de la decadencia de la cultura Wari, los pueblos se establecieron en las altas y estratégicas cumbres, donde rodeado de grandes murallas, se asentaron en habitaciones de forma circular, y produjeron burdos y toscos objetos de cerámica. Circunstancia en la que tuvieron contacto con los Incas.

Palabras claves: Chanka, Wari, Periodo Intermedio Tardío.

\section{Abstract}

In this article, after presenting the characteristics of the archaeological sites called Chanka, which correspond to the Late Intermediate Period, within the so-called Chanka Historical Area, it is discussed why, after the decline of the so-called Wari Empire, called peoples settled In the high and strategic summits, where surrounded by great walls, settled in rooms of circular form, and produced crude and crude objects of ceramics. Circumstance in which they had contact with the Incas.

KeYwoRds: Chanka, Wari, Periodo Intermedio Tardío.

\section{Asentamientos Chanka Durante el Periodo Intermedio Tardío}

La literatura arqueológica disponible que trata el caso del Periodo Intermedio Tardío o llamado Periodo Post-Wari, o sencillamente periodo Chanka, en lo que respecta a la sierra central peruana, que corresponde a los departamentos de Apurímac, Ayacucho y Huancavelica, sostienen que después de la caída de la hegemonía Wari, en estas zonas cercanas a la ciudad capital de Wari, se presentó una 
turbulencia e inestabilidad política, que consistió en desplazamientos demográficos, que motivó a los pueblos a establecerse en lugares estratégicos como la cima de los cerros; según muchos, con fines claramente militares (Earls y Silverblatt 1979) y que ".... fueron grupos humanos que se establecieron en pueblos ubicados entre los 2000 y 3500 m.s.n.m., en elevaciones escarpadas de difícil accesibilidad, con un equipo cultural diferente a Wari y sin antecedentes en la región. Se abandona la vida urbana y se implantan pequeños poblados rurales" (González 1992:32), y que según Sarmiento de Gamboa (1943:112-113) eran pueblos soberbios y guerreros, que más tarde se enfrentaron a los del Cuzco en tiempos del Inka Wiracocha (Rostworowski 1988, González 1992) y estos pueblos con el pasar de los tiempos se integraron en una Confederación Chanka (González 1992, Lumbreras 1969, Bendezú 1986).

Los grupos étnicos que formaron la llamada nacionalidad o Confederación Chanka, estuvieron unidos cultural y socialmente (González 1992: 83), como también por vínculos de origen mítico legendario, como el de haber surgido de la laguna de Choclococha (Pacarina) y otros vínculos más (Rostworoswki 1988). Estos, como lo menciona Lorenzo Huertas, fueron muchos grupos étnicos, que en Andahuaylas se denominaban Chankas; Tanquiguas en Vilcashuaman; los Soras y Rucanas en Lucanas; los Huainacondores y Huamanes en Huamanga; los Quispellaqta en Pomabamba; los Cochas, Mayos y Chinchaysuyos en Huanta y los Chocorbo, Chancas, Angaras, Astos y Huancas en el departamento de Huancavelica (Huertas 1990). A todo esto en la literatura arqueológica se le denomina Chanka, y al espacio geográfico que ocupó se lo denomina "área histórica Chanka", confederación Chanca o simplemente Chanca, (González, Pozzi-Escot y Vivanco 1988); al margen de las observaciones justificadas hechas por Bauer y otros (2013), en el sentido que “.... ha sido empleado de forma indiscriminada-y aún lo es- para aludir a los pueblos" que vivían en las jurisdicciones de las regiones de Huancavelica, Ayacucho y Apurímac, en el Perú central, al momento de la expansión incaica, cuando en realidad, según las fuentes históricas los Chancas estuvieron situados solo dentro de la región de Andahuaylas.

Estos sitios arqueológicos llamados Chanka, dentro del llamado Área Histórica Chanka, presentan características comunes, tales como: son asentamientos establecidos en zonas altas y estratégicas de las cumbres, cuyos asentamientos están rodeados en muchos casos de grandes murallas, que presentan estructuras habitacionales de forma circular, y están asociados a objetos de cerámicas burda y toscamente elaborados. Sitios con estas particularidades los ubicamos en las zonas de Vilcashuaman, donde Carlos Chahud ha encontrado más de 20 sitios (Chahud 1969), sumándose a ello el sitio arqueológico de Pillucho (Torres 1969); para la parte norte de la región de Ayacucho, cercanías del río Mantaro, Bonavía (1972) ha encontrado sitios arqueológicos en zonas defensivas. En Julcamarca, provincia de Angaraes del departamento de Huancavelica, existen sitios arqueológicos ubicados en la cima de los cerros: como Ñaupallaqta, Panco, Unaw, Comas y San Cristóbal (Bendezú 1986). Para la provincia de Churcampa, Huancavelica, el suscrito ubicó al sitio arqueológico de Toronjana, además los sitios de Tunapuquio (Valdez 2003) y de Lloqte Orqo, este último en las alturas de la comunidad de Ccotcoy. Para la provincia de Tayacaja, Churcampa, tenemos el sitio de Vaca Urqu (Valdez 2003). Para la provincia de Acobamba, en Marcas, se ubicó el sitio de Tinyaq (Valdez 2003). Socorro Quispe ubico algunos sitios para el caso de Vinchos, Huamanga (Quispe 1984). Lidio Valdez, Cirilo Vivanco y Casimiro Chávez (1990) identificaron ocho sitios arqueológicos que están ubicados por encima de los 3500 m.s.n.m. y que llegan hasta los 4050 m.s.n.m. en las inmediaciones de la margen izquierda de la cuenca del río Qaracha, en la provincia de Víctor Fajardo; como también se ha ubicado los sitios arqueológicos de Muyu Orqo, Linero Qasa, Piruruyuq, Hatun Kañay, Llaqtallaqta 1 y 2, Llaqtapata y Chiqkri en las cumbres altas de la margen derecha del río Qaracha en las inmediaciones de Huamanquiquia, en Víctor Fajardo (Vivanco, Valdez y Pizarro 2015: 24); para la parte intermedia entre el valle de Huanta y la cuenca de Ayacucho, en la cima del cerro de Allcowillca, están los sitios arqueológicos de Molinuyoq (González y Gálvez 1987:19-24; González 1992) y de Piruruyoq (Valdez 2003); en las 
alturas de la ciudad de Huamanguilla, Huanta, el sitio de Quriwillka (González, Pozzi-Escot y Vivanco 1988), el sitio de Torongana para la zona de Huayllay, distrito de Luricocha, al norte de la ciudad de Huanta, (Valdez 2003). Para el caso de Iquicha, provincia de Huanta, el suscrito describe el sitio arqueológico de Raqaraqay (Valdez 2014) que queda en la cuenca superior del río Torobamba. Para la zona de Chungi, provincia de La Mar, Pompeyo Ichaqaya ha reportado un caso parecido, donde todos los sitios arqueológicos se ubican por encima de los 3800 m.s.n.m. (Ibid); para el caso de Andahuaylas, Paulino Quispe informó sobre la existencia de sitios ubicados en partes elevadas (Valdez 1993). Para la cuenca de Paras y Totos, cuenca superior del Río Pampas, tenemos información de que presentan casos similares (Boris Peña, información personal en mayo 2008), y similar caso se presenta para la cuenca de Lircay (Paul Dillon, información personal en Mayo del 2008), igualmente para la cuenca del río Uras, provincia de La Mar, se ha reportado sitios como Allkuwillka, Bañico y Muyu Urqu, que presentan dichas características (Valdez 2009).

\section{Discusión}

Las características que presentan los sitios arqueológicos Chanka, dentro de la llamada "área histórica Chanka" (Gonzalez, Pozzi-Escot y Vivanco 1988), nos invita a formularnos algunas interrogantes, para entender cuáles fueron las posibles causas que impulsó a estas gentes a vivir en zonas de ubicación estratégica de altura y dentro de una zona ecológica llamada Puna, que supera los 3,000 m.s.n.m. para arriba: ¿La circunstancia de la caída de los Wari tiene que ver algo con la ubicación de los asentamientos de la cultura Chanka? ¿Cuáles fueron las causas para la caída de los Wari? ¿Qué causas empujó a los Chankas a ubicarse en zonas elevadas, especialmente en zonas estratégicas? ¿Será la violencia que empujó a estos pueblos a establecerse en zonas estratégicas? De ser la violencia, ¿quiénes protagonizaron esta violencia? ¿Serán los conflictos internos o externos que obligaron a los Chankas a vivir en zonas estratégicas y de altura? ¿Desde cuándo se establecieron bajo este patrón? ¿Y dónde se establecieron los que generaron esta violencia y empujaron a los pueblos a zonas de altura? Si la violencia fue entre ellos ¿por qué los Chankas se enfrentaron a los Inkas de manera conjunta?

Partamos discutiendo por qué Wari llega a su colapso. Los investigadores han dado algunas alternativas. Paulsen dicen que Wari no supo establecer el superávit económico necesario para mantener el aparato estatal, pero no nos explica porque no pudo establecer el superávit económico; otros como Willey creen que Wari cae frente a enemigos, Isbell cree que por una causa de crisis climática, como sequía, que obligó al abandono de la ciudad de Wari; Williams ha sugerido que el fin del dominio Wari se vio acelerado por el degradamiento de las condiciones medioambientales, que consecuentemente disminuyó las oportunidades para la intensificación agraria en los Andes en esa época (Bauer et al 2012:83); Menzel cree que por pugnas internas colapsó Wari (Bonavía 1991: 421). Según González, (2007) Wari fue invadida por otros pueblos que irrumpieron en territorio ayacuchano. Pero, lo cierto es que al final las ciudades Wari fueron abandonados, de manera violenta y rápida. Los trabajos de campo dan a entender de una posible caída violenta de la hegemonía Wari, que acarreó una masiva movilización poblacional. Tal es así, que al investigar los sitios Wari, los arqueólogos han informado un comportamiento que refuerza esta tesis: Anders (1989) ha informado que el sitio arqueológico de Azángaro había caído en medio de la violencia; igualmente ocurrió con el caso de Jinkamoqo (Schreiber 1987), similar fue el caso de Jargampata (Isbell 1977), que después de la fase 2B del Horizonte Medio los pueblos de la cuenca del río Torobamba San Miguel, La Mar, se establecieron en lugares estratégicos y generalmente en las partes altas. Durante los trabajos llevados a cabo en el sitio Wari de Chillikupampa, provincia de Huanta, se ha registrado evidencias de un abandono rápido y violento, y como testimonio aparecen dentro de los recintos arquitectónicos vasijas intencionalmente rotas con piedra, y que fueron abandonados (Figuras 04 y 05) (Valdez 2006), similar conducta pasó en el sitio arqueológico Wari de Marayniyuq (Valdez et al 2000). 


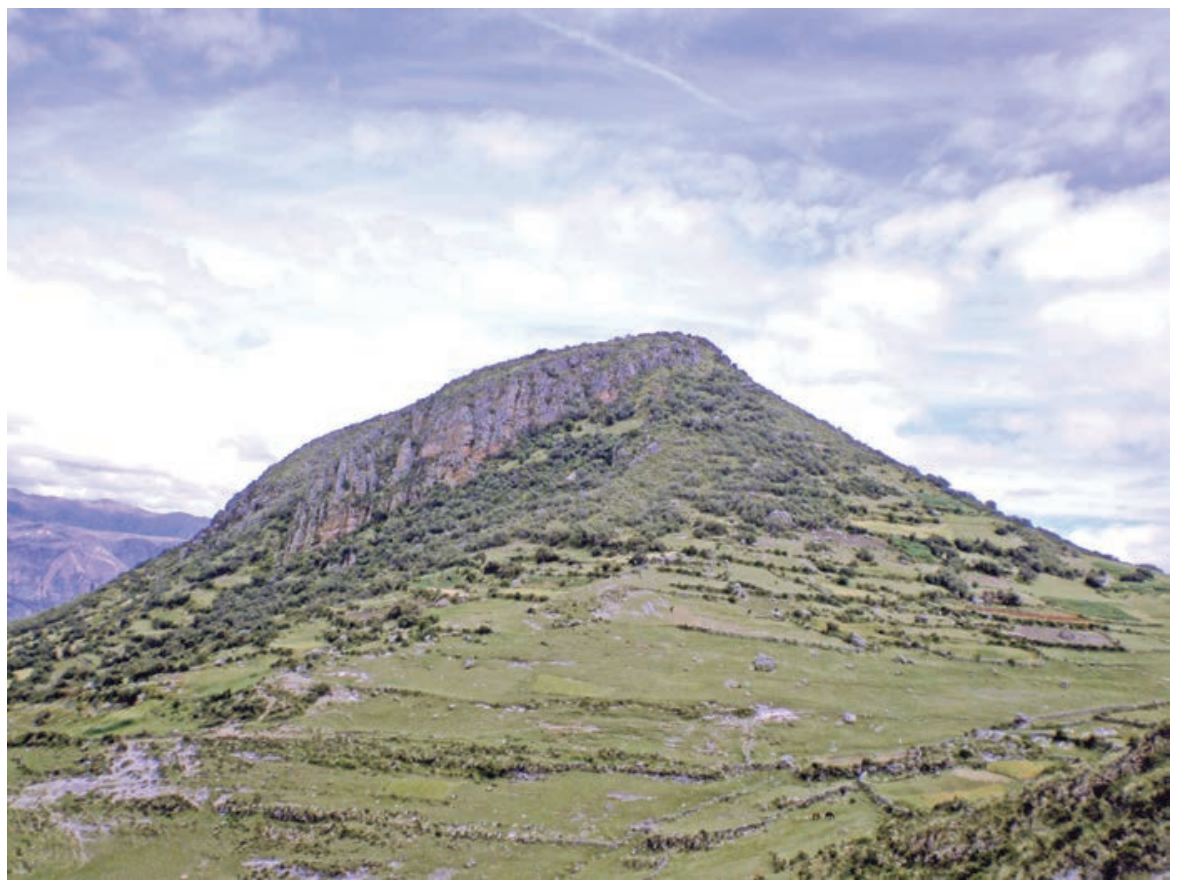

Figura 1: Sitio Chanka de Pillucho en las alturas de Vilcashuaman, Ayacucho.

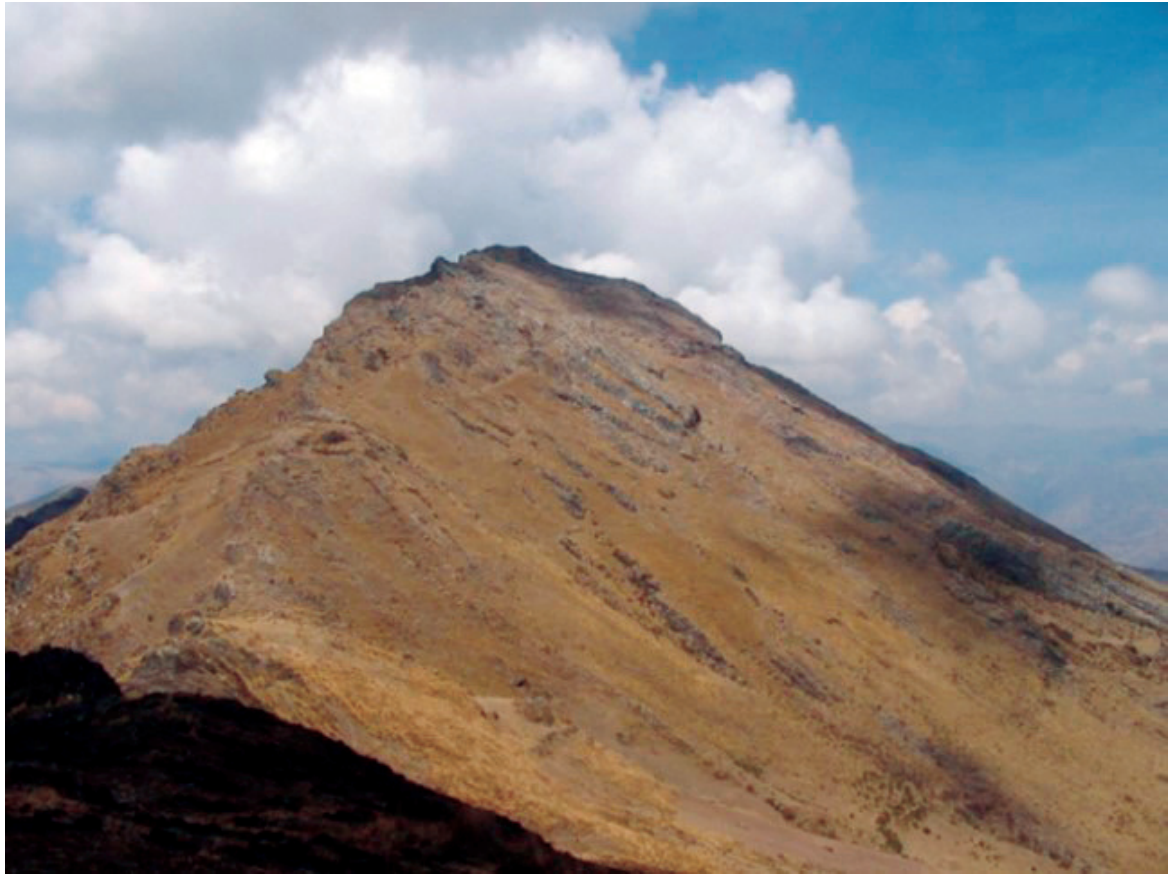

Figura 2: Véase el cerro Bañico, en la cumbre el sitio arqueológico Chanka 


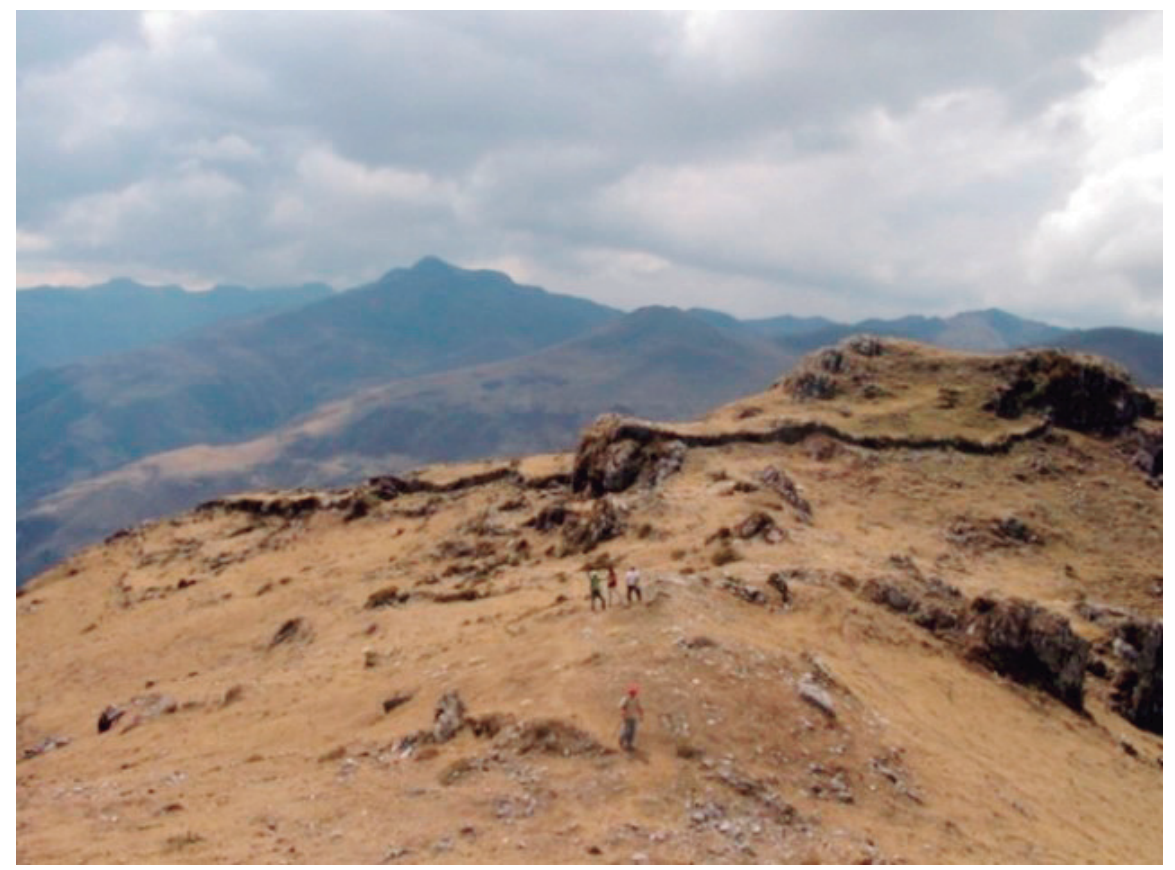

Figura 3: Vease la cumbre del cerro Bañico, el sitio arqueológico rodeado de una gran muralla.

Entendiendo que en la vida de la gente "las condiciones naturales fueron siempre condicionantes, pero en ningún caso determinantes” (Bravo 1995:32). Partamos de explicar esta conducta, teniendo en cuenta lo que ha planteado Cardich, quien "ha estudiado las glaciaciones climáticas, e indica que a partir del año 800 d. C. se inició un "corto" optimun climaticum que favoreció la agricultura; el hombre logró elevar los cultivos a niveles superiores a los 4,000 metros de altura. En esas circunstancias se originaron desplazamientos de pueblos a zonas más altas, ampliándose los límites territoriales de las antiguas agrupaciones sociales" (Huertas 1990). Similar fenómeno climático, también el cronista Martin de Murua logra registrar como una versión legendaria, dentro de los espacios del "Área Histórica Chanka", cuando se refiere al enfrentamiento que tuvieron los capitanes Guaman y Guanca, donde Guanca preso: “.... echo a huir a su gente y soldados, los cuales con el gran miedo que llevaban de los contrarios y por ir más ligeros echaron su huallca que llevaban de maíz en una pampa junto a unos cerros, $y$ en una laguna que ellos llamaban Acha, en la cual laguna dicen que en el tiempo de los calores se secó la dicha laguna y con la humedad de aquel asiento broto el maíz y produjo choclos y por este respeto fue llamado aquel asiento y lugar Choclococha" (Gonzalez 1994: 76). Lidio Valdez en lo que corresponde a la cuenca del río Warpa, norte de Ayacucho, ha ubicado a los sitios arqueológicos y ha diferenciado que los sitios Huarpa estaban establecidos en las partes más bajas a diferencia de los sitios Wari, y los sitios Wari más abajo que los sitios Inka; y por su puesto los sitios Chanka por encima de todos (Valdez 2004: 3-17). Bauer, citando a Thompson et al, y Binford et al, plantea que durante este periodo en los Andes hubo cambios climáticos “distinguido por condiciones más secas" (Bauer et al 2013: 91). En el estudio de los Astos, contemporáneo con los Chankas, Lavallee y Julien consideran que la conducta del límite agrícola desde la época prehispánica no puede explicarse sino por un cambio climático (1983: 69) ya que consideran que para el hemisferio austral hubo variaciones climáticas, y para el caso peruano, al margen de que no existen estudios sobre el caso, nos presentan los argumentos de Oppenheim, a 
propósito del glaciar Tullpa Raju, (Cordillera Blanca y Cordillera de Huaylas) que plantea que los “.... restos de construcciones humanas demuestran que hace más de 500 años el hombre nativo habitaba la misma región en alturas superiores, lo cual indica el desigual y esporádico movimientos de los hielos" (Lavallee y Julien 1983:70). Y para terminar, Lavallee y Julien sostienen que los Astos estuvieron claramente influenciados o "empujados" por los cambios climáticos (Ibid: 128).

Todo esto es muestra clara de que en tiempos prehispánicos hubo cambios climáticos, y estas desde luego tenían implicancias en la vida de las gentes. Eventos como esto nos presenta Waldemar Espinoza (1987:37) para el caso de los Aymaras, que su desplazamiento de sur a norte y las causas de la caída de los puquina (o tiahuanacos) pudieron ser por cambios también climáticos o como lo plantea Arkush la caída de Tiwanaku debió darse por el prolongado periodo de severo cambio climático (Bauer et al. 2012: 94).

Pudo haber ocurrido algo similar para el abandono de los sitios Wari. Posiblemente, los principales valles donde se estableció los sitios Wari, como en las cuencas del río Warpa, una parte del río Mantaro, para el caso del valle de Huanta; las cuencas de los ríos Pampas y Qaracha, para las zonas de Víctor Fajardo, Cangallo y Vilcashuaman; las cuencas del río Torobamba, para el caso de La Mar; las cuencas de los ríos Chichas y Soras, y otras cuencas más de la llamada “Área Histórica Chanka”, que llegan a tener en su mayoría una profundidad por debajo de los 2000 m.s.n.m. obviamente llegaron a presentar temperaturas altas, que hizo de estas una zona endémica propia de zonas tropicales, donde con facilidad pudieron proliferar enfermedades infecto contagiosas, producidas por insectos y otras plagas, que fácilmente amenazaron a los habitantes de los asentamientos Wari, obligándolos a buscar nuevas zonas fuera del alcance de ciertas enfermedades.

Entonces cabe la posibilidad, que lo que ocasionó que los sitios Wari fuesen abandonados, sería el cambio climático que estuvo acompañado por ciertas enfermedades, y que esperamos que futuras investigaciones interdisciplinarias clarifiquen esta posibilidad.

Utilizando los datos etnológicos y antropológicos, cabe mencionar que en las comunidades campesinas andinas, a la enfermedad se les considera como si fuera un ser vivo. La enfermedad, llamada Onqoy, se desplaza por los caminos, entra a las casa por la puerta. Se impregna en nuestra ropa. Se mete a nuestras casas. Y está en nuestros objetos. Posiblemente por eso los Wari, abandonaron sus asentamientos destruyendo intencionalmente sus vasijas de cerámica (Figura 04 y 05), tal como se registró en el sitio de Chillikupampa (Valdez 2006), (Figura 06), y en otros sitios Wari como Marayniyuq, sobre el piso se encontró varias, concentraciones de vasijas rotas, una molienda y un vaso (Valdez et al 2000), que invita suponer que fueron destruidas intencionalmente, para luego abandonar el sitio. O dando como una especie de ofrendas o pagapus, tal como los esposos Ochatoma (2000) registran para el caso de Conchopata, de la que consideran que fue “.... para establecer comunicación con sus divinidades... que viene a ser un acto ritual de tributación a través de la entrega de una ofrenda con el objeto de obtener un favor determinado". Se ha registrado en Chillikupampa entierros de cuerpos humanos en posición fetal a poquísima profundidad en las esquinas internas de los recintos rectangulares, en una cantidad de cinco, de la que se piensa que también formaron parte de un sacrificio para aplacar la furia de la plaga (Figura 07); lo que fue práctica común en Wari, tal como lo encontró Isbell en Conchopata (2000:19), o como menciona Rostworowski (2002:16): “.... las creencias animistas intentan aplacar los fenómenos naturales con ofrendas, cuya máxima expresión es el sacrificio humano"; y agrega que: "A través de los sacrificios y de las ofrendas el hombre desea controlar los temibles fenómenos naturales sobre los cuales no tiene poder. Con las ceremonias cree controlar los flagelos producidos por la naturaleza, como las enfermedades, y al complacer a los dioses espera obtener beneficios" (Ibid: 22). Allí estuvo la enfermedad, según la cosmovisión de ese entonces y como aún se piensa ahora en muchas comunidades. Actualmente en 

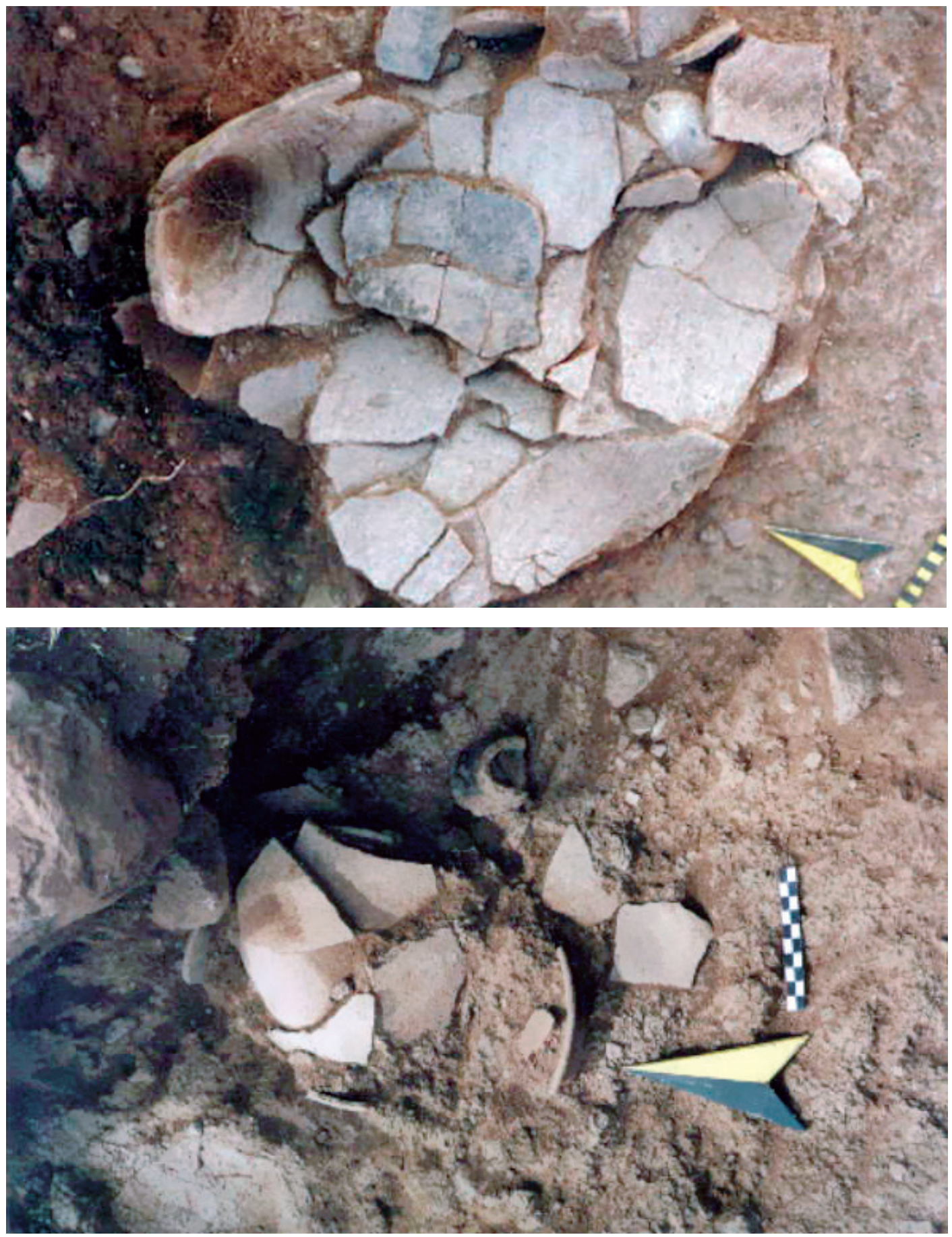

Figuras 4 y 5: Vasijas de cerámica destruidas intencionalmente en Chillikupampa 
los Andes, al menos en Ayacucho, es una práctica común hacer el Qaqupa para desprenderse de las enfermedades. El Qaqupa, consiste que con maíz molido, con pétalos de flores de claveles, pétalos de rosas blancas y otros ingredientes, se cubre y se frota todo el cuerpo del enfermo y luego este desecho se bota lejos. Y allí dentro de ese desecho está la enfermedad. Por eso hay que botarlo lejos, muchas veces en un lugar donde el camino se bifurca en varios ramales para que la enfermedad se confunda, y tome otra ruta. ¿Por qué no pensar que en Wari la gente abandonó sus casas para alejarse de la enfermedad? Y por eso rompió las vasijas intencionalmente y abandonó los sitios Wari buscando otras zonas y se refugió en zonas altas.

Aun en la fecha en las partes bajas de esta región, como el valle de San Miguel, Huanta, y las cuencas bajas del río Pampas son zonas endémicas donde son frecuentes las enfermedades. Aproximadamente en los años 1979, una anciana llamada Justina Casafranca Gómez, de 105 años de edad, de la comunidad de Chonta, que queda en las alturas donde el río Warpa afluye con el río Mantaro, en el distrito de Marcas, provincia de Acobamba, departamento de Huancavelica, preguntado por su nieto Edgar Pacheco Pedroza, ¿Por qué no vivimos en las partes bajas, cerca al río? Le respondió de que "allí podemos enfermarnos rápido" "wakpiqa apuraw manmiunqura muchuwam” (Información personal de Edgar Pacheco Pedroza julio 2015). Y esto posiblemente pasó en otras cuencas más con este cambio climático que nos presenta Cardich (Huertas 1990) y razón por la que las gentes no poblaron estas zonas de manera permanente. Esto sin negar, de que las zonas productivas fueron controladas desde las partes altas.

Pero se presentan algunos elementos en los asentamientos Chanka, que nos obligan a discutir su posible función. Me refiero que los sitios Chanka ubicados en zonas estratégicas, están rodeados de grandes muros y por zanjas en algunos casos, que hacen de los asentamientos zonas de difícil acceso. Esta conducta nos hace pensar naturalmente que fue para la defensa en un posible conflicto. Razón por que muchos investigadores sostienen que “.... luego de la caída Wari, esta región fue escenario de importantes conflictos, optando sus pobladores por establecerse en lugares estratégicos, de manera especial en la cima de las montañas que dominan toda el área circundante, y así poder contrarrestar cualquier incursión ofensiva" (Valdez, Vivanco y Chávez 1990:17-26). Similar apreciación es de González, en el sentido de que "La ubicación en estos lugares tan accidentados lleva a pensar que los pobladores tuvieron necesidad de hacer sus viviendas en lugares estratégicos desde los cuales se dominaba el territorio y se podía adoptar acciones defensivas frente a cualquier ataque" (González 2007:108).

Cabe preguntarse:¿Será para defenderse de alguna incursión en especial? o ¿fue necesario hacer muros y zanjas para defenderse de las enfermedades? Pero sería necesario recordar que las sociedades andinas, como muchas sociedades antiguas, tuvieron un mundo complejo de cosmovisión. Según Espinoza (1987: 437) cuando se refiere a la sociedad Inka, menciona que “.... la magia y religión influian en la totalidad de los aspectos de la vida cotidiana y pública desde los individuos pertenecientes a las clases sociales más bajas hasta los personajes e instituciones del más alto nivel (....) la organización religiosa no podía ir separada de la administración civil o laica". Y las gentes no solo actúan pragmáticamente y utilitariamente, sino que construyeron muchas obras en nombre de sus dioses y creencias. Las grandes obras como las Líneas de Nazca, se supone que fueron con fines puramente religiosos relacionados con el culto al dios Con (Rostworowski 2002: 25), las pirámides de la costa peruana, las grandes obras de arte chavinense, los tallados de piedra de Tiahuanaco, y otros, obedecieron claramente a ese propósito. Entonces las obras como los muros y las zanjas, en algunos casos ciertas portadas de acceso a sitios Chanka, debieron obedecer a algunas creencias en la sociedad Chanka. ¿Y cuáles serían esas creencias?

Recordemos como fue la reacción de la población indígena con el Taki Onqoy, la enfermedad del canto, enfermedad que surgió entre los años 1560 y 1570. Donde ante la propagación de epidemias 


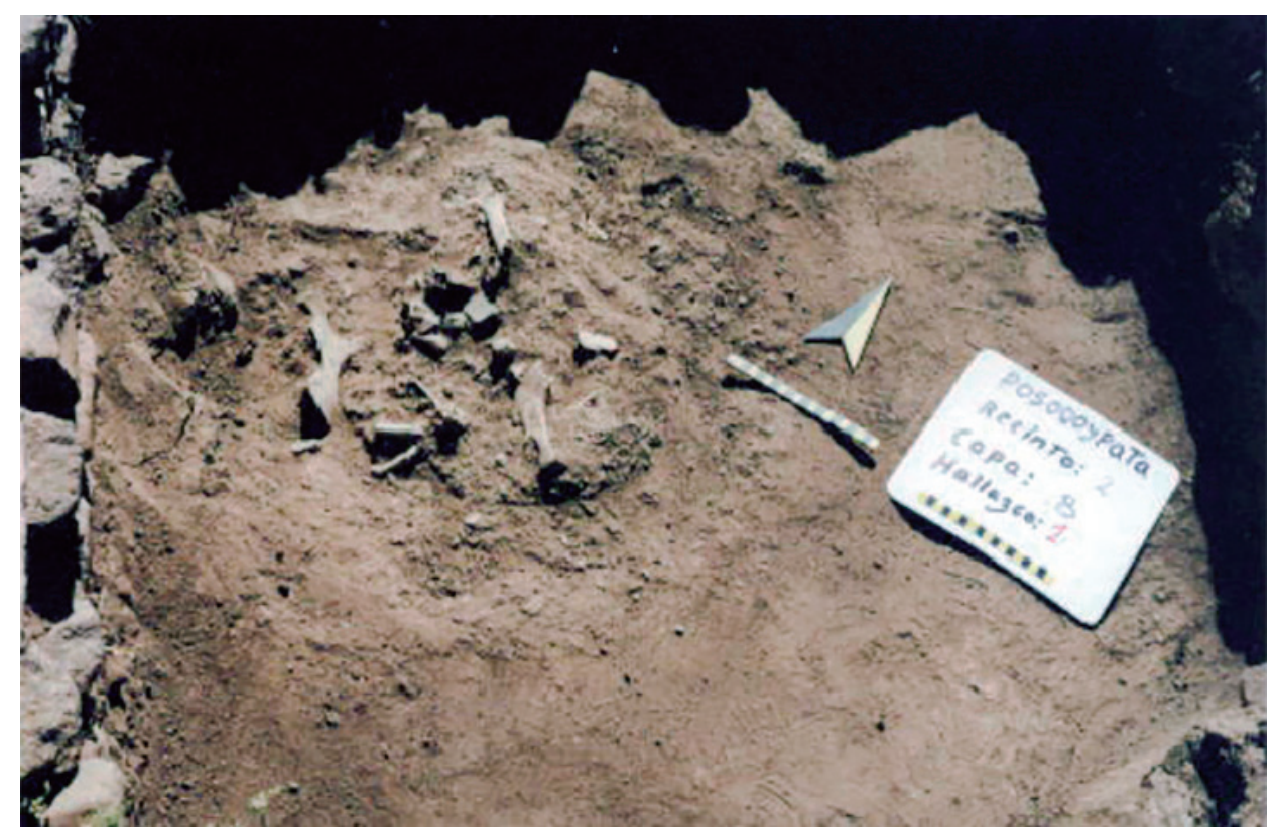

Figura 6: Ofrendas Wari antes de abandonar el sitio de Chillikupampa.

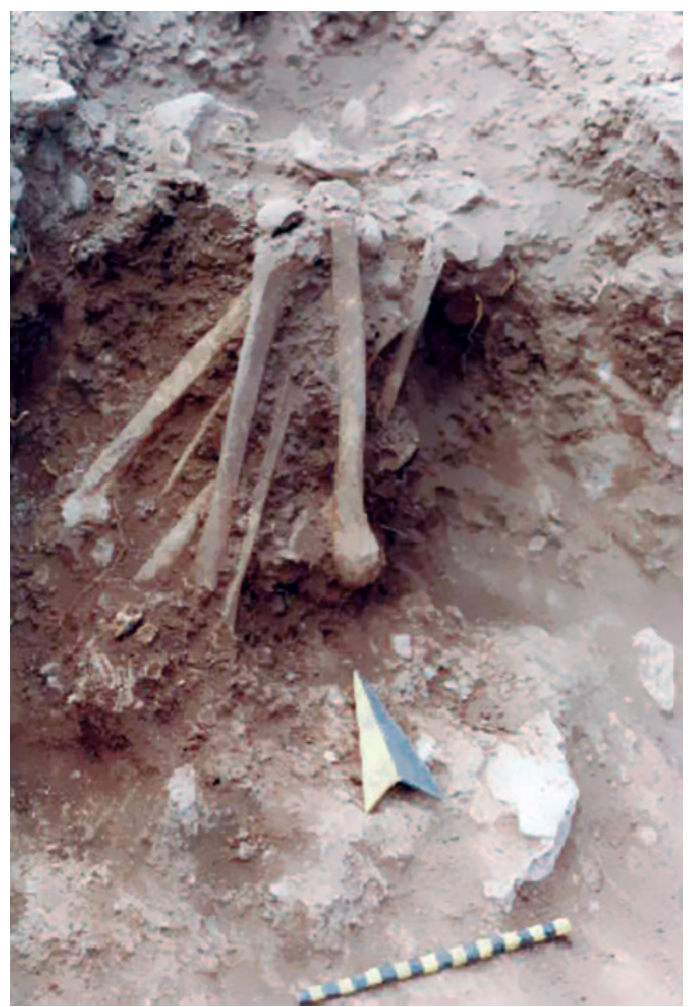

Figura 7: Ofrenda de un humano en el sitio de Chillikupampa antes de abandonar. 
mortales que diezmaban a la población indígena, profetas nativos, desde la región de Ayacucho, pasando de aldea en aldea, anunciaban que deberían de purificarse con ayunos y abstinencias sexuales y además deshacerse de cualquier objeto, indumentaria o costumbre de origen europeo, y en muchos casos los profetas invocaban a los habitantes a abandonar sus casas y a subir una montaña a hacer sacrificios y similar reacción fue con el Muru Onqoy que se desarrolló en 1590 (Curatola: 1986).

Viendo estos antecedentes de como las gentes reaccionaron ante posibles enfermedades, llamada "Onqoy", ¿podemos especular que la ubicación en zonas defensivas, circundado por muros y zanjas, era para alejarse del Onqoy? No será que el Onqoy fue la causante de la decadencia Wari. Porque en muchas excavaciones en sitios Wari, el contexto arqueológico, deja la impresión de que los ocupantes de un momento a otro destruyeron intencionalmente sus cosas, como vasijas, y abandonaron (ver Figura 03), (Valdez: 2005).

Otro aspecto a discutir, es ¿Por qué la calidad de la cerámica Wari: su iconografía y su forma cambió totalmente, para después presentarse con los Chankas con una cerámica burda y tosca? Siguiendo la misma tendencia de que la enfermedad es un ser vivo. Valdría considerar, que seguramente estas iconografías y figuras Wari, que eran representación de deidades waris, llegaron a ser asociados con el Onqoy. Tal vez se vio como una furia de los dioses, y por la que habría que hacer ofrendas (pagapus) sacrificios para desprenderse. Hay que recordar que en la cultura andina los dioses también podían ser olvidados o destruidos: "Estaban persuadidos que las divinidades no debían equivocarse en sus contestaciones; por eso cuando los acontecimientos resultaban al revés de lo que auguraban los oráculos, renegaban de ello y hasta los destruían; así procedió Atahualpa con el oráculo de Catequil en Porcón (Huamachuco)" (Espinoza 1987: 438). El mismo escenario nos ilustra Rostworowski, citando a Sarmiento de Gamboa: "Furioso Atahualpa marchó hacia el lugar donde se hallaba la huaca llevando una alabarda de oro en la mano (...) Luego ordenó allanar el templo y quemarlo" (Sarmiento de Gamboa, 1988: cap. 64). Tal vez por eso, no pudieron representar más las iconografías y ciertos patrones Wari en sus cerámicas Chanka, porque representarlos significaría llamar a la enfermedad (Onqoy).

De no ser así, lo que empujó a las gentes a vivir en estas zonas habría sido otras causas posiblemente de carácter social. Estas gentes que se establecieron en las cimas de los cerros, en toda esta área cultural Chanka. ¿Con quién tuvieron conflictos? ¿Con un enemigo foráneo y externo? ¿Con sus vecinos más cercanos?

Las evidencias arqueológicas nos sugieren, de que antes de la llegada de los Incas a estas zonas del Área Chanka, los Chankas ya estaban asentados en zonas estratégicas, es decir estaban ubicados en las partes más altas de los cerros, con fines claramente defensivos. Igualmente los Astos ya estaban ubicados en zonas por encima de los 3500 y 3800 m. (Lavallee y Julien 1983: 128). Entonces los Incas no fueron los que empujaron a los Chankas a vivir en estas zonas. De ser así, ¿quién fue ese enemigo externo? Hasta la fecha no se ha encontrado un asentamiento arqueológico diferente que amenazó a la nación Chanka. ¿Pudieran haber sido poblaciones costeñas, o tal vez algunas poblaciones selváticas tal como lo menciona Gonzales (1995)? Pero aún no hay evidencias. Entonces ¿que ha estado ocurriendo?

La llamada Área Cultural Chanka, tal como lo mencionamos, abarca una extensa área geográfica, y curiosamente dentro de esta configuración los patrones de asentamiento Chanka tienen las mismas características. ¿En todas estas zonas, un enemigo externo podría movilizarse con facilidad, teniendo a los Chankas ubicados en zonas estratégicas? ¿Es posible que dentro de una gran región, una incursión externa hiciera posible que toda la región tomara las mismas actitudes de refugiarse en las partes 
altas, mientras el enemigo de origen externo posiblemente contralara las partes bajas? Considerando que el Área Cultural Chanka es extensa, la reacción ante un enemigo externo no pudo presentarse de la misma forma. ¿Donde está la evidencia de ese enemigo de origen externo, que posiblemente controló algunas zonas? No hay evidencias.

De haberse presentado un conflicto entre ellos. ¿Es posible que las fuerzas beligerantes necesariamente tuvieran que ubicarse en las partes altas? En una contienda posiblemente una de las fuerzas tuvo más ventajas, y como tal no necesariamente tenía que ocupar las partes altas. Al menos habría de haber controlado algún valle. Pero de eso no tenemos evidencias. Pero si en este posible conflicto la finalidad era defenderse del enemigo. Habría al menos uno o dos sitios con características defensivas también ubicadas en alguna zona de valle, y no necesariamente todos por encina de los 3800 metros sobre el nivel del mar.

Cuando los Inkas incursionan en el área Chanka, los inkas encuentran a los Chankas unificados. Organizados en dos parcialidades. Entonces, ¿los Chankas con quien tuvieron conflictos?

Merece considerar además que este patrón de asentarse en las altas cumbres no es un caso exclusivo de los Chankas. Para Bauer y otros, esta época se encuentra caracterizada en todos los Andes por presentar cambios en sus asentamientos, puesto que pequeñas aldeas en el piso y en las laderas bajas de los valles fueron abandonadas, para establecerse en nuevos y más grandes asentamientos en las cumbres de las montañas y las cumbres de los cerros (Bauer et al 2013:91). Más aún, según el Proyecto de Investigación Arqueológica Alto Mantaro (UMARP) la construcción de los sitios del Periodo Intermedio Tardío en las cumbres de los cerros ha sido señalada para toda la sierra central (Bauer et al 2013:93). Así en los confines de Marcahuamachuco, después de Huari: “.... ahora la población de esta área comienza a ocupar poblados en las partes altas de los cerros, sobre los 3,000 m.s.n.m. lo que antes no sucedía. Estos asentamientos muestran un patrón de ordenamiento lineal, como consecuencia de estar situados sobre cumbres y crestas largas y estrechas de cerros donde en algunos casos está rodeadas de murallas y zanjas" (Bonavia 1991:502). Para el caso de la sierra central andina asistimos a un caso similar durante este periodo, como en Tarma, donde los sitios más importantes se alinean sobre las largas cumbres, crestas y laderas inclinadas de difícil acceso, a veces con sistemas de murallas defensivas. Similar caso se presenta en la región de: "Jauja donde los yacimientos se ubican en la cima de las colinas, al noreste de Jauja, hay una serie de sitios amurallados que oscilan entre los 3400 y 3850 m.s.n.m. Se encuentran en la cima de los cerros y se caracterizan por edificaciones circulares muy agrupadas y levantadas sin planeamiento" (Bonavia 1991: 508-509). Durante el periodo Intermedio Tardío, los asentamientos Huanca se ubicaban en lugares altos y fortificados. Sus casas eran de planta circular (Ravines 1994: 471). Caso similar se presenta con los Asto, grupo étnico ubicado entre los Huancas y los Chankas, donde los asentamientos están edificados en las cumbres de los cerros, en los puntos más elevados que dominan las punas, en muchas zonas rodeadas con murallas que los circundan en zonas poco inclinadas (Ibid: 491). Similar caso ocurre para el valle del rio Vilcanota como en las zonas del lago Titicaca (Bauer et al. 2013:93).

Tomando como ejemplo las experiencias vividas, durante la década del 80 del siglo pasados, cuando surgió el fenómeno subversivo en Ayacucho, curiosamente muchas comunidades abandonaron sus asentamientos originales que estaban ubicados en valles, y se establecieron en lugares estratégicos y en la cima de los cerros preferentemente, con fines claramente defensivos. Pero, para defenderse no de un enemigo foráneo, sino de un enemigo interno, en que muchos casos eran lo mismos comuneros o sus hijos, que estaban enrolados en grupos subversivos. Eso pasó en el valle de Huanta, en el valle del río Apurímac, en el valle de Torobamba, en el valle de Uras, bajo el nombre de "montucos". Aún 


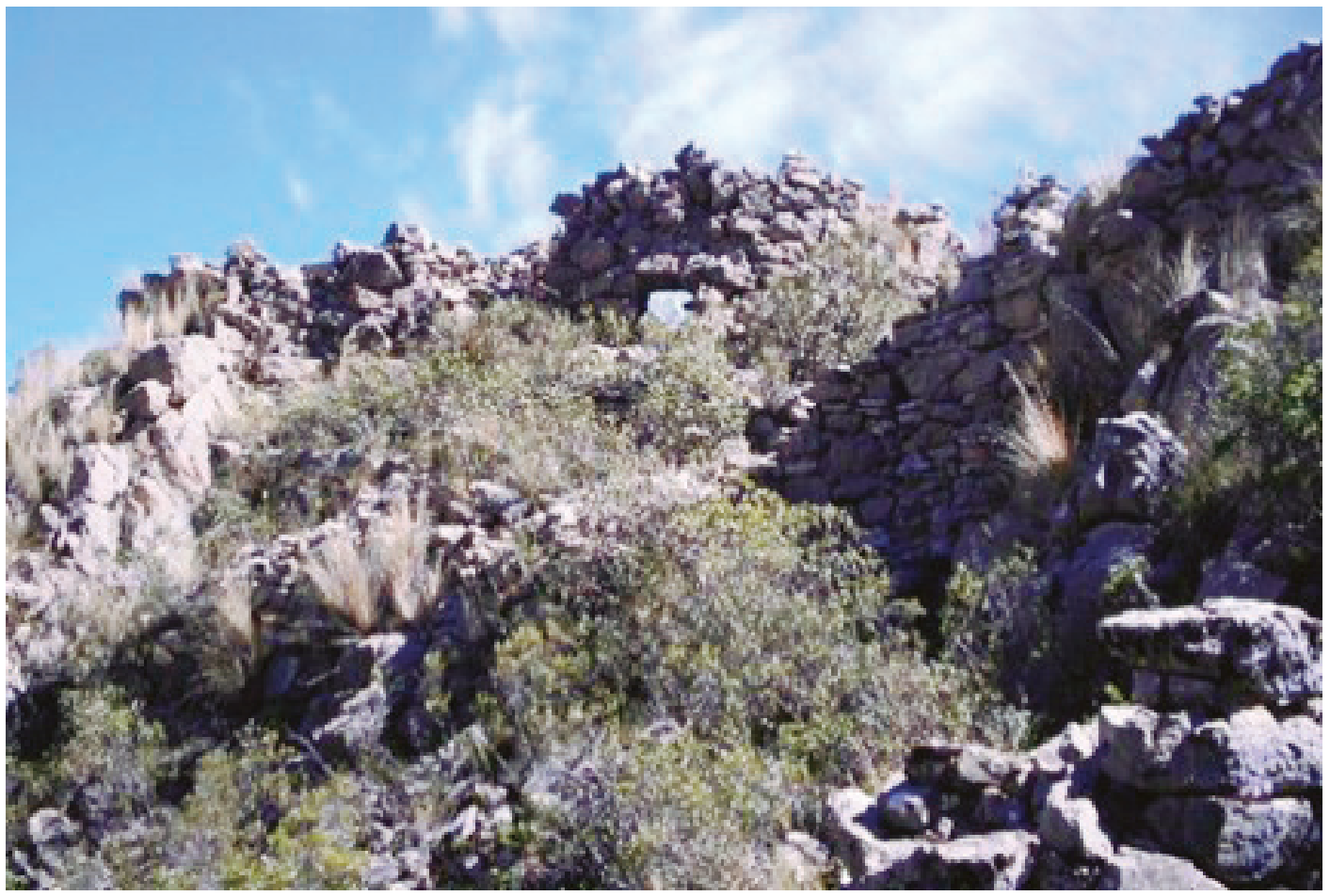

Figura 8: Vease la zona de acceso al sitio de Llaqtallaqta.

quedan vestigios de este tipo de asentamientos en estos valles. ¿Habría pasado algo similar durante estos tiempos con los Chankas?

En estos tiempos difíciles. Dentro de estos espacios que están ubicados en la cumbre de los cerros, se ha desarrollado actividades domésticas, tal como lo demuestran la presencia de fragmentos de cerámicas burdas de carácter doméstico, asociado a fogones, asociados a instrumentos líticos como moliendas y batanes que cumplieron una función también doméstica.

Este fenómeno de un posible conflicto social, no habría paralizado completamente la actividad productiva, como la agricultura y la ganadería. Es posible que estas gentes, continuaran trabajando sus campos en las partes bajas y valles que los circundan, tal vez no con la misma intensidad que se daba en tiempos de paz. Caso similar también pasó en la década de los 80 del siglo pasado en estas zonas, la gentes retornaban por las tardes a sus asentamientos ubicados en zonas estratégicas, y de día bajaban a sus campos de cultivo o pastoreo. ¿Eso pudo haber sucedido en estos tiempos de los Chankas? Posiblemente algo similar pudo haber pasado. Aún no lo sabemos.

\section{CONCLUSIONES:}

La decadencia Wari pudo haber ocurrido como secuela de un fenómeno climático en los Andes Peruanos. El calentamiento producido en los valles interandinos tuvo implicancias en la salubridad de la gente, con sus secuelas de enfermedades propias de zonas tropicales, las mismas que empujó a los Wari a abandonar las partes bajas y buscar lugares fuera del alcance de las secuelas producidas por el fenómeno del calentamiento. Estas enfermedades fueron asociadas posiblemente con las figuras o las 
iconografías Wari que comúnmente se representaban en sus tejidos, vasijas, etc. lo que produjo una crisis en la cosmovisión Wari, que puede ser denominado como un Pachacutec, donde las iconografías Wari fueron asociadas con la enfermedad o como portadoras del mal, motivo por la que durante el periodo llamado Chanka, estas fueron abandonadas por completo, ya que recrearlas en la sociedad Chanka, implicaría llamar a la enfermedad llamada Onqoy. Seguramente por esta razón el abandono de los sitios Wari fue rápido y bajo algunos patrones rituales, motivo por lo que algunos objetos Wari, fueron destruidos intencionalmente y dejados in sito, tal como se ha venido encontrando en muchas excavaciones.

Durante el llamado Periodo Intermedio Tardío, en toda el área central andina, los asentamientos humanos, estuvieron ubicados en lugares elevados y estratégicos, por encina de los 3400 m.s.n.m. Esta conducta ocurre en los Andes desde Cajamarca hasta los confines de las mesetas del Collao, y por ende por Huánuco, Junín, Huancavelica, Ayacucho, Abancay, Cuzco y los confines del Altiplano. Todo esto fue motivado por el fenómeno climático, y como tal los Chankas, sin negar la existencia de sus posibles conflictos sociales que se expresaban en guerra, se ubicaron en zonas altas y estratégicas, encima de los 3400 m.s.n.m. a donde naturalmente los efectos de los climas cálidos de las zonas tropicales no lograban alcanzar.

\section{BiBLIOGRAFÍA}

ANDERS, Martha B.

1989 “Azángaro: estructura y función de un sitio planificado" (segunda parte). Boletín de Lima N 65, pp. 51-66. Editorial los Pinos.

AGUILAR, Trinidad

1988 “Las trampas para cazar camélidos". Llamichos y Paqocheros, pastores de llamas y alpacas. Centro de Estudios Andinos Cuzco.

BAUER, Brian; ARAOZ, Miriam y KELLETT, Lucas

2013 Los Chancas. Investigaciones Arqueológicas en Andahuaylas (Apurímac, Perú) IFEA. UIC. Lima.

BENAVIDES, Mario

1976 Yacimientos Arqueológicos de Ayacucho. Universidad de Huamanga, Ayacucho.

BENDEZU, Oscar

1986 Reconocimiento de seis sitios tardíos en Julcamarca. Tesis de bachiller en Arqueología, Universidad Nacional San Cristóbal Huamanga, Ayacucho.

BONAVIA, Duccio

1972 “Reconocimiento arqueológico en el área del Mantaro”. Arqueológicas 14: 11-40, Lima.

BONAVÍA, Duccio

1991 Hombre e Historia. Desde los orígenes al siglo XV. Editorial Edubanco, tomo I. Lima, pp. 329-430. 1991. 
BRAVO, Gonzalo

1995 "Historia del mundo antiguo. Una introducción crítica". Alianza Editorial. Madrid.

CARRILLO B., Hernán

1969 Investigaciones Arqueológicas en la Provincia de La Mar. Universidad Nacional de San Cristóbal de Huamanga. Ayacucho, Perú.

1984 Inventario Arqueológico de Tambo y San Miguel, Ayacucho. Universidad Nacional de San Cristóbal de Huamanga. Ayacucho, Perú.

CASTILLA RIVERA, Adán

2000 Presencia de Pobladores Rurales durante el Intermedio Tardío en el distrito de Chilcas. Universidad Nacional de San Cristóbal de Huamanga. Ayacucho, Perú.

CHAHUD, Carlos

1969 Exploraciones arqueológicas en la provincia de Huanta. Universidad de Huamanga, Ayacucho.

EARLS Jhon e Irene SILVERBLATT

1979 Ayllus y etnias de la región Pampas-Qaracha, el impacto del imperio incaico. Investigaciones II: 267282. Universidad de Huamanga, Ayacucho.

ESPINOZA Waldemar

1987 Los Incas. Economía sociedad y estado en la era del Tahuantinsuyo. Amaru Editores. Perú.

CURATOLA, Marco

1986 “Mito y milenarismo en los Andes: del TakiOnqoy a Inkarri”. En: Allpanchis № 10, pp. 65-95. Cusco.

GONZÁLEZ, Enrique

1992 Los Señoríos CHANKAS. Universidad Nacional de San Cristóbal de Huamanga. Instituto Andino de Estudios Arqueológicos. Lima.

2007 Historia Prehispánica de Ayacucho. Lluvia Editores. Lima.

GONZALEZ, Enrique; POZZI-ESCOT, Denise y Cirilo VIVANCO

1988 El área histórica Chanka. Universidad Nacional de San Cristóbal de Huamanga. Laboratorio de Arqueología.

GONZÁLEZ, Enrique y José GÁLVEZ

1987 “Molinuyoq: Terrazas y reservorios en un pueblo prehispánico de Ayacucho”. Boletín de Lima № 53, año 9.

HUERTAS, Lorenzo

1990 “Los Chancas y el proceso disturbativo en los andes”. Historia y Cultura № 20, pp. 11-49. Museo Nacional de Historia. INC. Perú.

ISBELL, William

2000 "Repensando el Horizonte Medio: El caso Conchopata, Ayacucho, Perú". Boletín de Arqueología PUCP. № 4. 9-68. 
LAVALLEE Daniele y Michele Julien

1983 ASTOS: Curacazgo prehispánico de los Andes Centrales. Instituto de Estudios Andinos. Lima.

LUMBRERAS, Luis

1969 De los pueblos, las culturas y las artes del antiguo Perú. Lima.

1974 Las Fundaciones de Huamanga: hacia una prehistoria de Ayacucho. Club de Huamanga, Editores. Lima

OCHATOMA, José y Martha CABRERA

2000 “Arquitectura y áreas de actividad en Conchopata”. Boletín de Arqueología PUCP N 4, pp. 449488. Perú.

QUISPE CURI, Socorro

1984 "Prospección y reconocimiento arqueológico en el valle de Vinchos". Tesis de Bachiller. Ayacucho. Universidad Nacional de San Cristóbal de Huamanga.

RAVINES, Roger

1994 “Las culturas Preincas". Arqueología del Perú. Tomo I. Editorial BRASA.S.A. Lima.

ROSTWOROWSKI DE DIEZ CANSECO, María

1988 Historia del Tahuantinsuyo. Instituto de Estudios Peruanos. Lima.

1997 Pachacutec y la Leyenda de los Chancas. Instituto de Estudios Peruanos. Lima.

2002 Pachacamac. Instituto de Estudios Peruanos. Lima.

TORRES, Palomino, Jorge LISANDRO

1969 Investigaciones arqueológicas en Pilluchu. Ayacucho, Universidad Nacional de San Cristóbal de Huamanga (manuscrito).

VALDEZ, Julio Ernesto

2003 “Pueblos del Periodo Intermedio Tardío”. En: Revista Arqueológica Warpa, N 3: 03-27. Huanta. Imprenta Huanta.

2004 "Raqaraqay: Fortín de los Rebeldes Chankas. Más tarde convertido en base de operaciones del Iquichano José Antonio Navala Huachaca?” Revista Arqueológica Warpa. N 7, pp 22-35. Huanta-Perú.

2006 "Marcas: Testimonio de una larga historia". Revista Municipal N 1 del distrito de Marcas. Acobamba, Huancavelica.

2006 "Patrones de enterramiento prehispánico en Pusuquypata-Huanta". Revista Arqueológica Warpa $\mathrm{N}^{\circ} 12$.

2009 “Presencia Chanka en la cuenca del río Uras, San Miguel, La Mar. Tardío”. Revista Arqueológica Nº 14, pp. 09-14. Huanta. Perú.

VALDEZ, Lidio

1993 “Los orígenes, auge y Colapso del Imperio Wari”. WAMANI N 6, pp 90-110. Colegio de Antropólogos del Perú. 
2004 "De Wari a Inka: la antigua ocupación humana del valle de Ayacucho, Perú". Revista Warpa $\mathrm{N}^{\circ}$ 6. 2004.

VALDEZ, Lidio; VALDEZ, Ernesto; BETTCHER, Katrina y Cirilo VIVANCO

2000 “Marayniyoq, un establecimiento Wari en el valle de Ayacucho, Perú”. Boletín de Arqueología PUCP. Nº 4 pp. 549-564. Perú.

VALDEZ, Lidio; VIVANCO, Cirilo y Casimiro CHÁVEZ

1990 "Asentamiento Chanka en la cuenca del Pampas y Qaracha, Ayacucho". Gaceta Arqueológica Andina 5 (17): 17-26. Lima. Instituto Andino de Estudios Arqueológicos.

VIVANCO, Cirilo; VALDEZ, Ernesto y Antonio PIZARRO

2015 "Poblados prehispánicos tardíos en Huamanquiquia, Fajardo-Ayacucho. El Ayllu Lukana en Qarachawayqu”. Revista Arqueológica Warpa N 15: 17-29. Huanta. 